\title{
Recognising Colorectal Cancer in Primary Care
}

\author{
Natalia Calanzani (D) - Aina Chang · Marije Van Melle • \\ Merel M. Pannebakker · Garth Funston · Fiona M. Walter
}

Received: February 24, 2021 / Accepted: March 24, 2021 / Published online: April 17, 2021

(C) The Author(s) 2021

\begin{abstract}
Colorectal cancer (CRC) is the third most common cancer worldwide. Primary care professionals can play an important role in both prevention and early detection of CRC. Most CRCs are attributed to modifiable lifestyle factors, which can be addressed within primary care, and promotion of population-based screening programmes can aid early cancer detection in asymptomatic patients. Primary care professionals have a vital role in clinically assessing patients presenting with symptoms that may indicate cancer, as most patients with CRC first present with symptoms. These
\end{abstract}

N. Calanzani · M. Van Melle - M. M. Pannebakker · G. Funston · F. M. Walter ( $\square)$

Primary Care Unit, Department of Public Health and Primary Care, University of Cambridge, Cambridge CB1 8RN, UK

e-mail: fmw22@medschl.cam.ac.uk

A. Chang

School of Clinical Medicine, Addenbrooke's

Hospital, University of Cambridge, Cambridge, UK

F. M. Walter

Centre for Cancer Research and Department of

General Practice, University of Melbourne,

Melbourne, Australia assessments are often challenging-many of the symptoms of CRC are non-specific and commonly occur in patients presenting with nonmalignant disease. The range of options for investigating symptomatic patients in primary care is rapidly growing. Simple tests, such as faecal immunochemical testing (FIT), are now being used to guide decisions around referral for more invasive tests, such as colonoscopy, while direct access to specialist investigations is also becoming more common. Clinical decision support tools (CDSTs) which calculate cancer risk based on symptomatology, patient characteristics and test results can provide an additional resource to guide decisions on further investigation. This article explores the challenges of CRC prevention and detection from the primary care perspective, discusses current evidence-based approaches for CRC detection used in primary care (with examples from UK guidelines), and highlights emerging research which may likely alter practice in the future.

Keywords: Colorectal cancer; Early diagnosis; Faecal immunochemical test; Primary care 


\section{Key Summary Points}

Colorectal cancer (CRC) is the third most common cancer worldwide; primary care has a key role in its prevention and early detection.

Symptom assessment in primary care is challenging as CRC symptoms are often common and non-specific, but there are several options to guide decisions around referrals and examinations.

This article provides a practical resource for primary care professionals, describing current evidence-based approaches and emerging research for the early detection of CRC, including the increasing role of the faecal immunochemical test (FIT) for triaging symptomatic patients in primary care.

\section{DIGITAL FEATURES}

This article is published with digital features, including a summary slide, to facilitate understanding of the article. To view digital features for this article, go to https://doi.org/10.6084/ m9.figshare.14270441.

\section{INTRODUCTION}

Colorectal cancer (CRC), comprising cancers of the colon and rectum, is the third most common cancer type and the second most common cause of cancer death worldwide, with over 800,000 deaths globally in 2018 [1-3]. Most CRCs develop from adenomatous polyps or adenomas; the most common subtype of CRC is adenocarcinoma (85\% of cases) [4]. CRC diagnosed at later stages is associated with shorter survival time [5]. In England, while 5-year agestandardised survival rates are 91.7\%, 84.1\% and $64.9 \%$ when CRC is diagnosed in stages I, II and III (respectively), this is reduced to $10.3 \%$ when diagnosed with metastases at stage IV [6].

In countries where general practitioners (GPs) play a gatekeeping role, patients usually present first in primary care with symptoms that may indicate cancer. However, many of the gastrointestinal symptoms caused by CRC, such as change in bowel habit, are common, often non-specific, and most people presenting with them will not have cancer [7-9]. This presents a key diagnostic challenge for GPs-how to promptly identify the small number of symptomatic patients with cancer from the large number without? To facilitate this, a number of guidelines, diagnostic tools and strategies have been developed.

This review offers a practical resource for primary care professionals when assessing patients with possible CRC symptoms. First, we discuss the epidemiology of the disease and the role of CRC screening, outlining how primary care may contribute to this. Then, we focus on the clinical assessment of patients in primary care, providing specific UK examples (with relevance to primary care in other countries). Finally, we highlight promising diagnostic developments.

This article is based on previously conducted studies and does not involve any new studies of human or animal subjects performed by any of the authors.

\section{EPIDEMIOLOGY AND RISK FACTORS}

Globally (although with substantial heterogeneity), age-standardised incidence rates for CRC have increased in the past 30 years [10]. Increases are occurring in less developed countries in Eastern Europe, Asia and South America, while trends towards stabilisation or decreased rates are noted across highly developed countries such as the UK [3]. Beyond population ageing, rises in incidence can be attributed to changes in lifestyle including alcohol consumption, obesity, smoking, limited physical activity and poor diet (i.e. red and processed meat consumption, insufficient fibre and calcium) $[3,4,10-12]$. Figure 1 describes several 


\section{Protective lifestyle factors}

- Consumption of dietary fibre

- Consumption of whole grains

- Consumption of dairy products

- Milk intake

- Calcium intake

- Physical activity

- Aspirin use

- Hormone replacement therapy

\section{Lifestyle risk factors}

- Consumption of processed meat

- Consumption of red meat

- Alcohol consumption

- Body fatness

- Abdominal fatness

- Tobacco smoking

Fig. 1 Protective and risk factors for colorectal cancer. Source: Created with evidence from [4, 14]

\section{Higher risk groups}

(Including genetically determined conditions)

- Family history of CRC

- Personal history of CRC or colorectal adenoma

- Other diseases/conditions

- Inflammatory bowel disease

(ulcerative colitis and Crohn's disease)

- Acromegaly

- Ureterosigmoidostomy

- Cystic fibrosis

- Non-polyposis syndromes

- Lynch syndrome

- Familial CRC

- Adenomatous polyposis syndromes (e.g. Familial Adenomatous Polyposis or FAP)

- Non-adenomatous polyposis syndromes

- Genetic variants lifestyle factors which can protect or increase CRC risk. In the USA, CRC has the second highest number of cancer cases and deaths attributed to lifestyle factors [11]. In the UK, over half of CRC cases can be attributed to lifestyle factors [12]. For primary care, the key implication is that behaviour change interventions, such as those focusing on diet or physical activity, may help to reduce CRC burden [13].

In contrast with incidence rates, age-standardised mortality rates (again with substantial heterogeneity) have decreased worldwide [10]; this has been attributed to the introduction of organised screening programmes and other strategies to promote early cancer diagnosis (e.g. urgent referral pathways; rapid access to diagnostics), and improvements in treatment $[3,4,10]$.

Worldwide, CRC is more common in men than women (a 1.47 male-to-female ratio in incidence rates) [4]. CRC risk increases with age, with nine in ten cases diagnosed among people aged 50 years and older $[15,16]$. Nevertheless, recent studies in developed countries (including the USA, Canada, Australia and the UK) show significant increases in incidence rates among those under 50 [17-20]. It is important to be mindful of these changes when assessing younger patients presenting with relevant symptoms in primary care.

Certain populations are at a higher risk of CRC (Fig. 1); these include those with genetic conditions such as Lynch syndrome [4]. Personal history of colorectal adenomas and/or family history of CRC (a two-fold increase in risk if a first-degree relative has CRC) are also known risk factors [4]. Other conditions that increase CRC risk include the main inflammatory bowel diseases (IBDs) ulcerative colitis and Crohn's disease, particularly if conditions are untreated, severe, or are present for a longer time period [4]. Surveillance is often recommended in these cases [21-23].

\section{SCREENING}

Organised CRC screening programmes aim to identify cancer in asymptomatic patients (when the disease is more likely to be at early stage) 
and has been shown to reduce CRC mortality [24-28]. Screening also facilitates removal of adenomas and other polyps before they become cancerous, helping to prevent CRC [4]. Population-based CRC screening is well established in several countries worldwide (including the UK, USA and Australia), with variation in the screening tests used, time intervals and eligibility criteria [29]. In England and Wales, people aged between 60 and 74 are invited by post to participate in a biannual screening programme; the age threshold is lower in Scotland (50-74 years) [30]. While population-based CRC screening is not usually carried out in primary care, substantial international and UK evidence show that primary care endorsement (such as sending personalised reminder letters or discussing pros and cons of screening with patients) has a key role in improving CRC screening participation [31-37].

The faecal immunochemical test (FIT) was recently introduced in the $\mathrm{UK}$, replacing the guaiac faecal occult blood test (gFOBT) to detect occult blood in asymptomatic individuals [38]. FIT has several advantages over gFOBT, including an increased sensitivity and specificity, better sensitivity to detect advanced adenomas, and only requires a single stool sample. FIT is specific to human haemoglobin, does not require dietary restrictions, and the results are unaffected by the use of non-steroidal anti-inflammatory drugs (NSAIDs) and anticoagulants [39-42]. Using FIT instead of gFOBT also increases screening participation [40, 43-46]. FIT thresholds/cut-off points for screening vary, even across UK countries (currently $80 \mu \mathrm{g} / \mathrm{g}$ in Scotland, $120 \mu \mathrm{g} / \mathrm{g}$ in England and $150 \mu \mathrm{g} / \mathrm{g}$ in Wales) [47-49]. Those with a result at/above the threshold are referred for a colonoscopy. In addition to FIT, individuals aged 55 in some UK areas are invited to participate in a 'one-off' screening sigmoidoscopy, estimated to have led to a $26 \%$ reduction of CRC incidence two decades post-intervention [50].

Organised screening identifies a minority of CRCs, with a recent study involving six highly developed countries estimating from $6.3 \%$ to $31.4 \%$ of all diagnoses [51]. In England, the most recent National Cancer Registration and Analysis Service analysis of routes to diagnosis show the proportion to be $8 \%$ (from 2006 to 2016) [52]. This highlights the need to engage with screening to maximise informed participation, and also shows the vital role of clinically assessing patients presenting with symptoms in primary care for CRC - this is how most patients with the disease present.

\section{SYMPTOMATIC PRESENTATION IN PRIMARY CARE}

Most patients diagnosed with CRC will have presented in primary care with one or more abdominal complaints before diagnosis $[53,54]$. Lower gastrointestinal symptoms require clinical and family history, physical examination (including abdominal and rectal examination), and routine blood tests (to exclude anaemia and other clinical features) [55]. Symptoms may overlap for cancer and other non-malignant gastrointestinal conditions such as diverticular disease or diverticulitis, IBD, and irritable bowel syndrome (IBS). Figure 2 describes the National Institute for Health and Care Excellence (NICE) guidance (adopted in England, Wales and Northern Ireland) for diagnosing such conditions when cancer is not suspected [56-58]. Safety-netting is required if no causes for the presenting symptoms are identified and they persist over time $[59,60]$.

CRC has a broad symptom signature (Fig. 3) with varying predictive value [61]. Rectal bleeding is a common presenting symptom although wide variation is reported across studies (16-60\%); a large proportion of patients with CRC will not present with this symptom $[61,62]$. Other common presenting symptoms are abdominal pain, weight loss, tiredness and changes in bowel habit, particularly looser or more frequent stools [61]. Important clinical features of CRC are iron-deficiency anaemia, abdominal tenderness and abnormal rectal examination [63]. If multiple symptoms/features are present, this increases the likelihood of a patient having CRC but positive predictive values (PPV; the chance of a patient with a symptom/feature combination having cancer) rarely exceed $10 \%[9,63]$. 


\section{Diverticular disease}

Suspect diverticular disease if:

- Intermittent abdominal pain in the left lower quadrant (right lower quadrant possible in a minority of people and in those of Asian origin) with constipation, diarrhoea or occasional large rectal bleeds AND/OR tenderness in the left lower quadrant on abdominal examination.

Do not routinely refer, unless:

- Routine endoscopy and/or radiology cannot be organised from primary care OR colitis is suspected OR patient meets criteria for a cancer pathway.

Guidance is also available for acute diverticulitis

\section{Inflammatory bowel disease (IBD)}

Suspect IBD if:

- Lower GI symptoms, particularly chronic abdominal pain/discomfort, with diarrhoea or constipation - but these symptoms are also common to other conditions (most often IBS). IBD is characterised by inflammation of the bowel (not present in most patients with IBS).

Faecal calprotectin (FC) testing is recommended to support differential diagnosis of IBD or IBS in adults with recent onset lower $\mathrm{Gl}$ symptoms for whom specialist assessment is being considered, IF: cancer is not suspected AND appropriate quality assurance processes and locally agreed care pathways are in place.

\section{Irritable bowel syndrome (IBS)}

Consider assessment if the following have been present for at least 6 months:

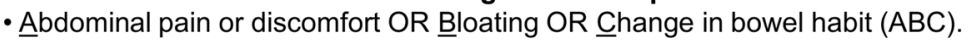

Only consider IBS diagnosis if:

- Abdominal pain or discomfort either relieved by defaecation or associated with altered bowel frequency or stool form, accompanied by at least two of the following four symptoms: altered stool passage (straining, urgency, incomplete evacuation); abdominal bloating (more common in women than men); distension, tension or hardness; symptoms made worse by eating; passage of mucus.

- Other features that may support diagnosis: lethargy, nausea, backache and bladder symptoms.

If criteria are met, undertake the following to exclude other diagnoses:

- Full blood count (FBC); erythrocyte sedimentation rate (ESR) or plasma viscosity; c-reactive protein (CRP); antibody testing for coeliac disease.

Fig. 2 Common non-malignant bowel conditions and associated NICE guidance. Source: created with evidence from NICE guidance [56-58]

\section{Symptoms and signs}

- Unexplained weight loss

Abdominal pain

- Unexplained rectal bleeding

- Change in bowel habit

- Rectal or abdominal masses

- Abdominal tenderness

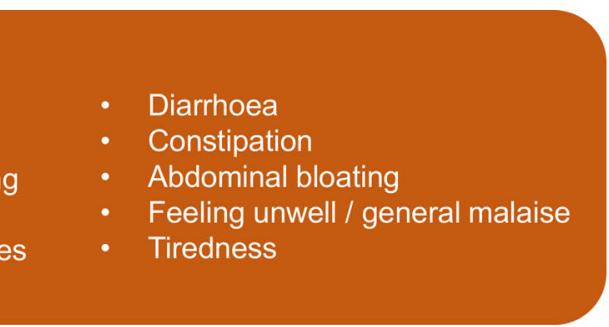

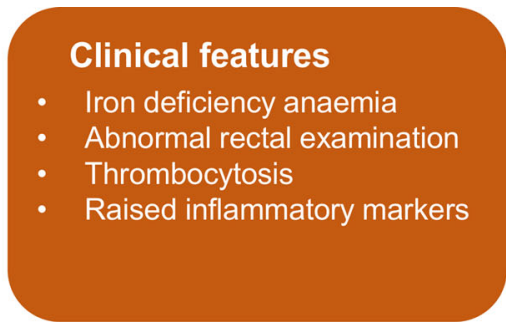

Fig. 3 Symptoms and clinical features that may indicate CRC. Source: created with evidence from [64-66]

There is also emerging evidence that raised platelet count (thrombocytosis) is a risk marker for different types of cancer, including CRC $[55,67]$. Raised inflammatory markers (C-reactive protein, erythrocyte sedimentation rate and plasma viscosity) are associated with an increased risk of cancer, but the sensitivity for these markers is too low to warrant their use to rule out CRC in primary care [68]. 


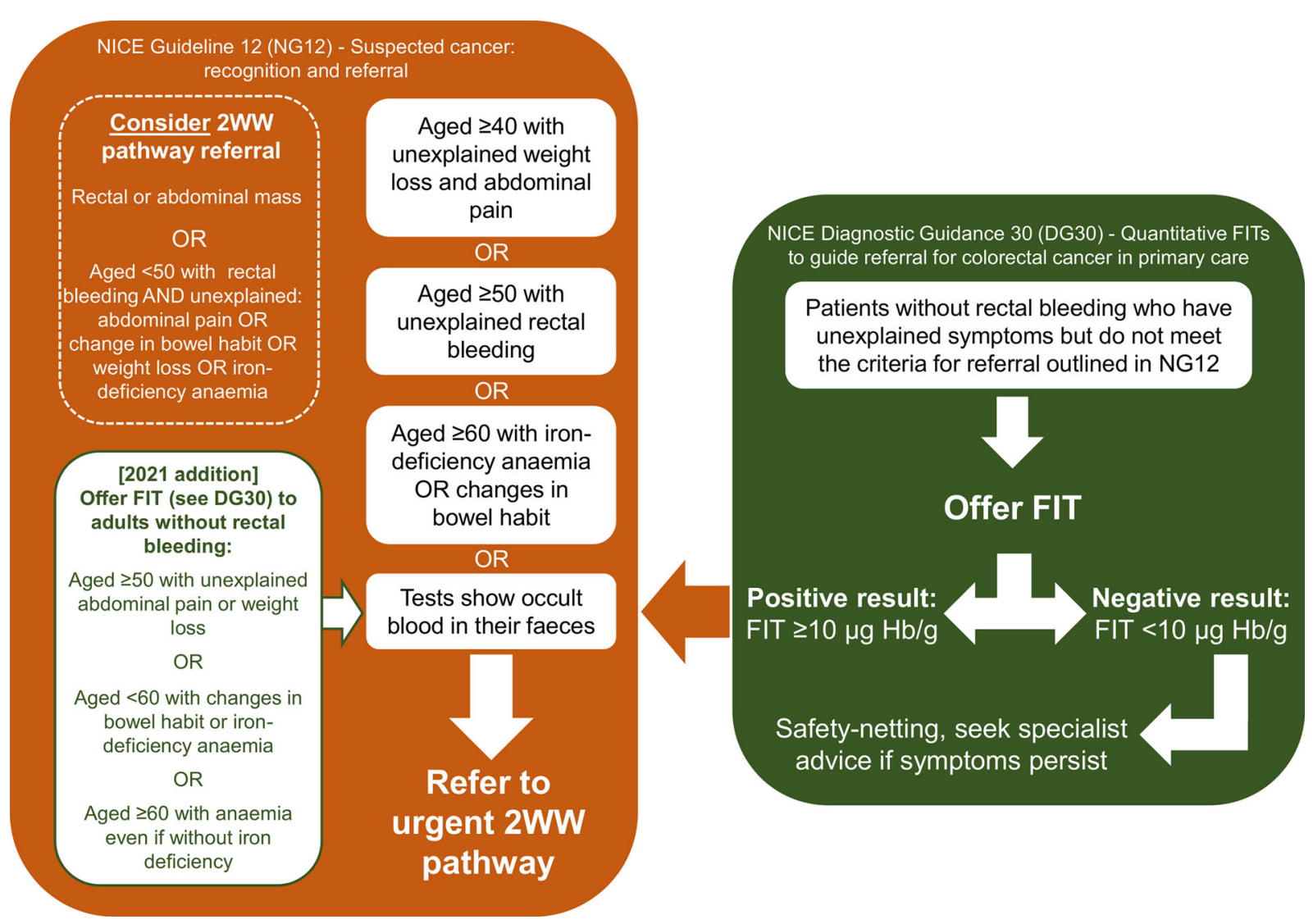

Fig. 4 NICE guidelines when there is a suspicion of CRC. Source: Created with evidence from $[38,65]$

\section{REFERRAL AND INVESTIGATIONS}

The 2015 NICE guidelines for patients with a suspicion of cancer (known as urgent or 2-week wait referrals) uses age-based symptom cut-offs for patients presenting with alarm or "red flag" symptoms and/or clinical features which have a PPV of 3\% or higher (Fig. 4) [65]. This pathway ensures that patients with such features have rapid diagnostic assessments, most often a colonoscopy. Increased use of the urgent referral pathway has shown to be significantly associated with lower CRC mortality, although no associations have yet been found between pathway use and reduction in late-stage cancers $[69,70]$.

Non-specific symptoms or vague, "low-risk but not no-risk symptoms" that do not meet the urgent referral threshold still carry a risk of cancer [63]; younger patients with such symptoms may also need to be investigated. The
2017 NICE guidelines DG30 [38] (Fig. 4) recommends these patients are offered FIT by GPs, using one of three FIT assays: OC Sensor, HMJACKarc or FOB Gold [38]. Specifically, FIT should be offered for patients without rectal bleeding who have unexplained symptoms that do not meet criteria for urgent referral. FIT for symptomatic patients uses a threshold of $10 \mu \mathrm{g}$ $\mathrm{Hb} / \mathrm{g}$ faeces-much lower than that adopted when FIT is used for screening (recognising the increase in risk for symptomatic patients). Because of the different thresholds, patients meeting criteria should still be offered a FIT even with a recent negative screening result. If the FIT result is positive, the patient can be urgently referred.

A review that informed NICE DG30 reported that at a $10 \mu \mathrm{g} \mathrm{Hb} / \mathrm{g}$ level, FIT had sensitivity between $92 \%$ and $100 \%$ and could rule out CRC in approximately $75-80 \%$ of all symptomatic patients. The negative predictive value (which 
takes into account disease prevalence) ranged from $99.4 \%$ to $100 \%[71,72]$. When the result is negative the clinician can be confident the patient is very unlikely to have CRC, and provide reassurance. Unnecessary colonoscopies or similar investigations are also avoided. Vigilance is crucial in primary care, both when results are positive and patients are not diagnosed with cancer, and when results are negative. While most patients with a positive FIT result will not have cancer (a recent study showed that $7 \%$ of those with a positive FIT had CRC) [73], many will have another significant bowel disease [72]. Since it is still possible (though very unlikely) that a patient with a negative FIT result has cancer, GPs should emphasise the need for patients to seek help if symptoms persist (safety-netting) [59].

Most of the studies that informed the NICE DG30 were carried out in secondary care populations, and only a few countries (including England, Australia and Spain) officially recommend using FIT in primary care to triage patients [74]. Since the guidelines were published, further studies have provided more evidence on FIT's utility in primary care, not only to rule out (most evidence) but also to rule in (least evidence) CRC [59, 73, 75-81]. While a recent survey of 1024 GPs in England found that less than half recognised DG30 [82], it is likely that awareness has increased recently owing to FIT availability, and the increasing use of FIT as a result of limited colonoscopy capacity exacerbated by the COVID-19 pandemic, including to triage patients referred on the urgent pathway $[83,84]$. While some guidance has been published on such use [85], evidence on its impact is still limited and it is unclear whether FIT will continue to be used as such (and to what extent) after the COVID-19 pandemic.

\section{DIAGNOSIS}

Colonoscopy remains the gold standard investigation for diagnosing colorectal cancer, with histological proof of diagnosis through a biopsy [64]. It is highly sensitive (89-98\% for adenomas of at least $10 \mathrm{~mm}$ in size, and $75-93 \%$ for adenomas of at least $6 \mathrm{~mm}$ in size), [42] and has a relatively low risk of complications, with low perforation (0.08-0.2 per 1000 procedures) and bleeding rates (0.8-2.4 per 1000 procedures) [4]. Alternative investigations are available to deal with limited colonoscopy availability and to meet patient needs when colonoscopy is contraindicated (e.g. frail elderly). These include flexible sigmoidoscopy and the less invasive CT colonography (also called virtual colonoscopy) [64]. While CT colonography is a safe alternative to colonoscopy, it has been found to be less sensitive for smaller polyps $[4,86]$ (this could be due to perceptual errors that may be improved with training) [87], has a lower detection rate for high-risk serrated lesions [88] and is associated with higher referral rates for additional examinations [89]. Colon capsule endoscopy (patient swallows a camera pill that takes pictures of the bowel as it passes through-these pictures are beamed to a recording device that the patient wears at their waist) is a new alternative. Previously only used in the specialist setting because of its high cost $[9,90]$, recent limited availability of colonoscopy and patient reluctance to undergo testing in hospital settings because of the COVID-19 pandemic has led to its evaluation as a triage test for moderate to high-risk symptomatic patients [91]. Colon capsule endoscopy is also being trialled in Scotland [92].

\section{RECENT AND FUTURE DEVELOPMENTS}

This section describes recent developments with applicability to primary care settings: electronic tools to aid risk assessment and triage, GP direct access to tests, development of rapid diagnostic centres, and use of novel biomarkers. Artificial intelligence may also aid CRC diagnosis in the future, but evidence is still limited $[9,93,94]$.

\section{Electronic Tools to Aid Risk Assessment and Triage}

Clinical decision support tools (CDSTs) have been developed to allow GPs to make the most 
of data available in patient medical records (such as symptoms, patient characteristics such as age and sex and test results) in order to calculate patients' risk of cancer [95-97] (Box 1).

\section{Box 1. Risk Prediction Tools and Models}

In the UK, the best known risk prediction tools are the electronic Risk Assessment Tools (eRATs) [63, 98], QCancer@ [99-101] and MacMillan Clinical Decision Support tools which combine eRATs and QCancer@ [102]. eRATs were derived from case-control studies in primary care and estimate cancer risk for each patient, describing the PPV for single or repeated symptoms [98]. A trial evaluating their clinical and cost effectiveness is under way [103]. QCancer $\odot$ was derived from a primary care database (QResearch); it estimates cancer risk for symptomatic or asymptomatic individuals, considering not only symptoms but other risk factors such as age, sex, smoking status and family history [99]. Recent evidence indicates that although widely available, such risk prediction tools are still underused in primary care [104]. While they may benefit clinical decision-making, several challenges with implementation have been highlighted $[105,106]$.

More recent risk prediction models combine patient data and results from biomarker tests. Examples include the CEDAR trial in the Netherlands which combined routine data with results from FIT and faecal calprotectin to rule out significant colorectal diseases [107], and the COLONPREDICT studies in Spain that validated a CRC prediction model based on clinical information and test results (FIT and other biomarkers) and developed a score (FAST) to predict CRC using FIT results, age and sex $[108,109]$. The FAST score has recently been evaluated in Scotland; results showed it did not enhance the utility of FIT used alone [110].

\section{Direct Access to Tests and Development of Rapid Diagnostic Centres}

Recognising challenges in diagnosing cancers with varied symptomatology, different diagnostic pathways have been pioneered in
Denmark, with urgent referrals for both alarm symptoms and serious, non-specific symptoms (GP triage is required for the latter-with direct access to investigations) and the use of diagnostic centres (also with direct access) for vague symptoms [111]. Similar approaches have been adopted in Norway and Sweden [112, 113], and tested in England as part of the "Accelerate, Coordinate, Evaluate" (ACE) programme [114-116]. Informed by ACE results, the 2019 National Health Service (NHS) long-term plan stipulates the creation of Rapid Diagnostic Centres (RDCs). These will initially focus on cancers associated with non-specific symptoms, followed by wider implementation for all patients with suspected cancer, including selfreferral for red flag symptoms [117, 118].

A key aspect of these new pathways is direct access to specialist tests and imaging, recognising evidence of health system factors (particularly GP gatekeeping) on cancer outcomes [119-121]. Earlier strategies in England already included specific investment on GP direct access to CT scans and flexible sigmoidoscopy $[122,123]$ and laboratory tests [124]. Nonetheless, substantial regional variation in access is acknowledged [125]. Wide variations are therefore likely in terms of access and availability of RDCs.

\section{Use of Novel Biomarkers}

There has been substantial research in the development of biomarkers other than FIT for the detection of CRC; these include proteins, volatile organic compounds, stool DNA and liquid biopsy (comprising circulating tumour cells and cell-free DNA) $[126,127]$. The methylated SEPT9 gene is a promising biomarker [128-131]. However, evidence is scarce for the primary care setting, and this makes clinical applicability uncertain because of spectrum effect/bias (variation in performance due to testing in different populations) [130, 132].

\section{CONCLUSION}

Primary care professionals have a vital role in the timely diagnosis of CRC. They can also help 
with prevention through behavioural interventions aiming at lifestyle changes and facilitating informed CRC screening participation. Importantly, most patients will present in primary care with lower gastrointestinal symptoms before being diagnosed. Diverse symptomatology requires the use of different pathways to diagnosis; guidance is available to facilitate this. Diagnostic tests to triage patients are available, along with promising emerging tools. Further innovations are required to deal with an increasing need for diagnostic investigations.

\section{ACKNOWLEDGEMENTS}

Funding. This study was supported by the CanTest Collaborative (funded by Cancer Research UK C8640/A23385). No funding or sponsorship was received for the publication of this article.

Authorship. All named authors meet the International Committee of Medical Journal Editors (ICMJE) criteria for authorship for this article, take responsibility for the integrity of the work as a whole, and have given their approval for this version to be published.

Authors' Contributions. NC, MvM, GF and FMW conceptualised the review. NC, MMP, and AC searched for evidence that informed this review. NC, AC, MvM and MMP analysed the evidence and interpreted it. NC drafted the initial manuscript with the support from AC, MMP and FMW. NC, AC, MvM, MMP, GF and FMW critically reviewed the manuscript draft and approved the final version.

Disclosures. This study was supported by the CanTest Collaborative (funded by Cancer Research UK C8640/A23385) of which Fiona M. Walter is Director, and Natalia Calanzani, Merel M Pannebakker and Garth Funston are researchers. The funder of the study had no role in study design, data collection, data analysis, data interpretation, or writing of the report. Garth Funston is a current member of the Oncology Editorial Board for Advances in
Therapy. Marije Van Melle works as a medical scientist at Optimum Patient Care UK and is currently involved in a study co-funded by AstraZeneca. Aina Chang has nothing to disclose.

Compliance with Ethics Guidelines. This article is based on previously conducted studies and does not involve any new studies of human or animal subjects performed by any of the authors.

Data Availability. Data sharing is not applicable to this article as no datasets were generated or analyzed during the current study.

Open Access. This article is licensed under a Creative Commons Attribution-NonCommercial 4.0 International License, which permits any non-commercial use, sharing, adaptation, distribution and reproduction in any medium or format, as long as you give appropriate credit to the original author(s) and the source, provide a link to the Creative Commons licence, and indicate if changes were made. The images or other third party material in this article are included in the article's Creative Commons licence, unless indicated otherwise in a credit line to the material. If material is not included in the article's Creative Commons licence and your intended use is not permitted by statutory regulation or exceeds the permitted use, you will need to obtain permission directly from the copyright holder. To view a copy of this licence, visit http:// creativecommons.org/licenses/by-nc/4.0/.

\section{REFERENCES}

1. GLOBOCAN 2018. Estimated number of incident cases worldwide, both sexes, all ages. 2020. https:// www.gco.iarc.fr. Accessed 9 Apr 2021.

2. GLOBOCAN 2018. Estimated number of deaths worldwide, both sexes, all ages. 2020. https://www. gco.iarc.fr. Accessed 9 Apr 2021.

3. Arnold M, Abnet CC, Neale RE, et al. Global burden of 5 major types of gastrointestinal cancer. Gastroenterology. 2020;159(1):335-49.e15. 
4. IARC. Colorectal cancer screening. 2019. https:// publications.iarc.fr/Book-And-Report-Series/IarcHandbooks-Of-Cancer-Prevention/ColorectalCancer-Screening-2019. Accessed 9 Apr 2021.

5. Maringe C, Walters S, Rachet B, et al. Stage at diagnosis and colorectal cancer survival in six highincome countries: a population-based study of patients diagnosed during 2000-2007. Acta Oncol. 2013;52(5):919-32.

6. Cancer Survival in England: adults diagnosed between 2013 and 2017 and followed up to 2018 . 2020. https://www.ons.gov.uk/peoplepopulation andcommunity/healthandsocialcare/conditionsand diseases/datasets/cancersurvivalratescancersurvival inenglandadultsdiagnosed. Accessed 9 Apr 2021.

7. Rubin G, Berendsen A, Crawford SM, et al. The expanding role of primary care in cancer control. Lancet Oncol. 2015;16(12):1231-72.

8. Emery JD, Shaw K, Williams B, et al. The role of primary care in early detection and follow-up of cancer. Nat Rev Clin Oncol. 2014;11(1):38-48.

9. Rubin G, Walter F, Emery J, et al. Reimagining the diagnostic pathway for gastrointestinal cancer. Nat Rev Gastroenterol Hepatol. 2018;15(3):181-8.

10. GBD 2017 Colorectal Cancer Collaborators. The global, regional, and national burden of colorectal cancer and its attributable risk factors in 195 countries and territories, 1990-2017: a systematic analysis for the Global Burden of Disease Study 2017. Lancet Gastroenterol Hepatol. 2019;4(12): 913-33.

11. Islami F, Goding Sauer A, Miller KD, et al. Proportion and number of cancer cases and deaths attributable to potentially modifiable risk factors in the United States. CA Cancer J Clin. 2018;68(1): 31-54.

12. Brown KF, Rumgay H, Dunlop C, et al. The fraction of cancer attributable to modifiable risk factors in England, Wales, Scotland, Northern Ireland, and the United Kingdom in 2015. Br J Cancer. 2018;118(8):1130-41.

13. NICE. Behaviour change: individual approaches. Public health guideline [PH49]. 2014. https://www. nice.org.uk/guidance/ph49. Accessed 9 Apr 2021.

14. World Cancer Research Fund. Diet, nutrition, physical activity and colorectal cancer. 2017. https://www.wcrf.org/sites/default/files/CUP\% 20Colorectal\%20Report_2017_Digital.pdf. Accessed 9 Apr 2021.
15. GLOBOCAN 2018. Estimated number of incident cases worldwide, both sexes, ages 50+. 2020. https://www.gco.iarc.fr. Accessed 9 Apr 2021.

16. GLOBOCAN 2018. Estimated number of incident cases worldwide, both sexes, ages 0-49. 2020. https://www.gco.iarc.fr. Accessed 9 Apr 2021.

17. Vuik FE, Nieuwenburg SA, Bardou $M$, et al. Increasing incidence of colorectal cancer in young adults in Europe over the last 25 years. Gut. 2019;68(10):1820-6.

18. Siegel RL, Fedewa SA, Anderson WF, et al. Colorectal cancer incidence patterns in the United States, 1974-2013. J Natl Cancer Inst. 2017;109(8):djw322.

19. Araghi M, Soerjomataram I, Bardot A, et al. Changes in colorectal cancer incidence in seven high-income countries: a population-based study. Lancet Gastroenterol Hepatol. 2019;4(7):511-8.

20. Loomans-Kropp HA, Umar A. Increasing incidence of colorectal cancer in young adults. J Cancer Epidemiol. 2019;2019:9841295.

21. Monahan KJ, Bradshaw N, Dolwani S, et al. Guidelines for the management of hereditary colorectal cancer from the British Society of Gastroenterology (BSG)/Association of Coloproctology of Great Britain and Ireland (ACPGBI)/United Kingdom Cancer Genetics Group (UKCGG). Gut. 2020;69(3):411.

22. Laine L, Kaltenbach T, Barkun A, et al. SCENIC international consensus statement on surveillance and management of dysplasia in inflammatory bowel disease. Gastroenterology. 2015;148(3):63951.e28.

23. NICE. Colorectal cancer prevention: colonoscopic surveillance in adults with ulcerative colitis, Crohn's disease or adenomas. Clinical guideline [CG118]. 2011. https://www.nice.org.uk/guidance/ CG118. Accessed 9 Apr 2021.

24. Zauber AG. The impact of screening on colorectal cancer mortality and incidence: has it really made a difference? Dig Dis Sci. 2015;60(3):681-91.

25. Gini A, Jansen EEL, Zielonke N, et al. Impact of colorectal cancer screening on cancer-specific mortality in Europe: a systematic review. Eur J Cancer. 2020;127:224-35.

26. Levin TR, Corley DA, Jensen CD, et al. Effects of organized colorectal cancer screening on cancer incidence and mortality in a large communitybased population. Gastroenterology. 2018;155(5): 1383-91.e5.

27. Logan RFA, Patnick J, Nickerson C, et al. Outcomes of the Bowel Cancer Screening Programme (BCSP) 
in England after the first 1 million tests. Gut. 2012;61(10):1439.

28. Hewitson P, Glasziou P, Watson E, et al. Cochrane systematic review of colorectal cancer screening using the fecal occult blood test (hemoccult): an update. Am J Gastroenterol. 2008;103(6):1541-9.

29. Young GP, Rabeneck L, Winawer SJ. The global paradigm shift in screening for colorectal cancer. Gastroenterology. 2019;156(4):843-51.e2.

30. Koo S, Neilson LJ, Von Wagner C, et al. The NHS Bowel Cancer Screening Program: current perspectives on strategies for improvement. Risk Manag Healthc Policy. 2017;10:177-87.

31. Hewitson P, Ward AM, Heneghan C, et al. Primary care endorsement letter and a patient leaflet to improve participation in colorectal cancer screening: results of a factorial randomised trial. $\mathrm{Br} \mathrm{J}$ Cancer. 2011;105(4):475-80.

32. Wardle J, von Wagner C, Kralj-Hans I, et al. Effects of evidence-based strategies to reduce the socioeconomic gradient of uptake in the English NHS Bowel Cancer Screening Programme (ASCEND): four cluster-randomised controlled trials. Lancet. 2016;387(10020):751-9.

33. Cole SR, Smith A, Wilson C, et al. An advance notification letter increases participation in colorectal cancer screening. J Med Screen. 2007;14(2): $73-5$.

34. Zajac IT, Whibley AH, Cole SR, et al. Endorsement by the primary care practitioner consistently improves participation in screening for colorectal cancer: a longitudinal analysis. J Med Screen. 2010;17(1):19-24.

35. Triantafillidis JK, Vagianos C, Gikas A, et al. Screening for colorectal cancer: the role of the primary care physician. Eur J Gastroenterol Hepatol. 2017;29(1):e1-7.

36. Shankleman J, Massat NJ, Khagram L, et al. Evaluation of a service intervention to improve awareness and uptake of bowel cancer screening in ethnicallydiverse areas. Br J Cancer. 2014;111(7):1440-7.

37. Calanzani N, Cavers D, Vojt G, et al. Is an opportunistic primary care-based intervention for nonresponders to bowel screening feasible and acceptable? A mixed-methods feasibility study in Scotland. BMJ Open. 2017;7(10):e016307.

38. NICE. Quantitative faecal immunochemical tests to guide referral for colorectal cancer in primary care (DG30). 2017. https://www.nice.org.uk/guidance/ dg30. Accessed 9 Apr 2021.
39. Nieuwenburg SAV, Vuik FER, Kruip MJHA, et al. Effect of anticoagulants and NSAIDs on accuracy of faecal immunochemical tests (FITs) in colorectal cancer screening: a systematic review and metaanalysis. Gut. 2019;68(5):866-72.

40. Young GP, Symonds EL, Allison JE, et al. Advances in fecal occult blood tests: the FIT revolution. Dig Dis Sci. 2015;60(3):609-22.

41. Steele RJC. Overview of colorectal cancer screening. Colorectal Dis. 2019;21(S1):14-5.

42. Lin JS, Piper MA, Perdue LA, et al. Screening for colorectal cancer: updated evidence report and systematic review for the US preventive services task force. JAMA. 2016;315(23):2576-94.

43. ISD Scotland. Scottish Bowel Screening Programme Statistics. For the two-year period of invitations between 1 May 2017 and 30 April 2019. 2020. https://www.beta.isdscotland.org/media/3401/ 2020-02-04-bowel-screening-publication-summary. pdf. Accessed 9 Apr 2021.

44. Vart G, Banzi R, Minozzi S. Comparing participation rates between immunochemical and guaiac faecal occult blood tests: a systematic review and metaanalysis. Prev Med. 2012;55(2):87-92.

45. Hol L, Wilschut JA, van Ballegooijen $\mathrm{M}$, et al. Screening for colorectal cancer: random comparison of guaiac and immunochemical faecal occult blood testing at different cut-off levels. Br J Cancer. 2009;100(7):1103-10.

46. Clark G, Strachan JA, Carey FA, et al. Transition to quantitative faecal immunochemical testing from guaiac faecal occult blood testing in a fully rolledout population-based national bowel screening programme. Gut. 2021;70(1):106-113.

47. Cancer Research UK. FIT bowel screening. Information for GPs in England. 2019. https:// publications.cancerresearchuk.org/publication/fitbowel-screening-england-gps-cancer-insight. Accessed 9 Apr 2021.

48. Cancer Research UK. Faecal immunochemical test. Bowel screening in Scotland. 2017. https://www. publications.cancerresearchuk.org/publication/fitbowel-screening-scotland-gps-cancer-insight. Accessed 9 Apr 2021.

49. Cancer Research UK. Faecal tmmunochemical test. Bowel screening in Wales. 2019. https://www. publications.cancerresearchuk.org/publication/fitbowel-screening-wales-gps-cancer-insight. Accessed 9 Apr 2021.

50. Atkin W, Wooldrage K, Parkin DM, et al. Long term effects of once-only flexible sigmoidoscopy 
screening after 17 years of follow-up: the UK Flexible Sigmoidoscopy Screening randomised controlled trial. Lancet. 2017;389(10076):1299-311.

51. Weller D, Menon U, Zalounina Falborg A, et al. Diagnostic routes and time intervals for patients with colorectal cancer in 10 international jurisdictions; findings from a cross-sectional study from the International Cancer Benchmarking Partnership (ICBP). BMJ Open. 2018;8(11):e023870.

52. National Cancer Registration and Analysis Service (NCRAS). Percentage of diagnoses by route-2006 to 2016. http://www.ncin.org.uk/publications/ routes_to_diagnosis. Accessed 9 Apr 2021.

53. Koo MM, von Wagner C, Abel GA, et al. The nature and frequency of abdominal symptoms in cancer patients and their associations with time to helpseeking: evidence from a national audit of cancer diagnosis. J Public Health. 2018;40(3):e388-95.

54. Moreno CC, Mittal PK, Sullivan PS, et al. Colorectal cancer initial diagnosis: screening colonoscopy, diagnostic colonoscopy, or emergent surgery, and tumor stage and size at initial presentation. Clin Colorectal Cancer. 2016;15(1):67-73.

55. Scottish Government. Scottish referral guidelines for suspected cancer. 2019. http://www. cancerreferral.scot.nhs.uk/lower-gastrointestinalcancer/?alttemplate=guideline. Accessed $9 \mathrm{Apr}$ 2021.

56. NICE. Diverticular disease: diagnosis and management (NG147). 2019. https://www.nice.org.uk/ guidance/ng147. Accessed 9 Apr 2021.

57. NICE. Faecal calprotectin diagnostic tests for inflammatory diseases of the bowel. Diagnostics guidance [DG11]. 2013. https://www.nice.org.uk/ guidance/dg11. Accessed 9 Apr 2021.

58. NICE. Irritable bowel syndrome in adults: diagnosis and management. Clinical guideline [CG61]. 2008. https://www.nice.org.uk/guidance/cg61. Accessed 9 Apr 2021.

59. Nicholson BD, James T, Paddon M, et al. Faecal immunochemical testing for adults with symptoms of colorectal cancer attending English primary care: a retrospective cohort study of 14487 consecutive test requests. Aliment Pharmacol Ther. 2020;17:17.

60. Nicholson BD, Mant D, Bankhead C. Can safetynetting improve cancer detection in patients with vague symptoms? BMJ. 2016;355:i5515.

61. Koo MM, Hamilton W, Walter FM, et al. Symptom signatures and diagnostic timeliness in cancer patients: a review of current evidence. Neoplasia. 2018;20(2):165-74.
62. Walter FM, Emery JD, Mendonca S, et al. Symptoms and patient factors associated with longer time to diagnosis for colorectal cancer: results from a prospective cohort study. Br J Cancer. 2016;115(5): 533-41.

63. Hamilton W. The CAPER studies: five case-control studies aimed at identifying and quantifying the risk of cancer in symptomatic primary care patients. Br J Cancer. 2009;101(2):S80-6.

64. National Collaborating Centre for Cancer. Suspected cancer: recognition and management of suspected cancer in children, young people and adults. Clinical guideline. Appendices A-E. London: National Collaborating Centre for Cancer. 2015. http://www.nice.org.uk/guidance/ng12/evidence/ appendices-ae-74333342. Accessed 9 Apr 2021.

65. NICE. Suspected cancer: recognition and referral NICE guideline [NG12]. 2015. https://www.nice. org.uk/guidance/ng12. Accessed 9 Apr 2021.

66. Renzi C, Lyratzopoulos G, Card T, et al. Do colorectal cancer patients diagnosed as an emergency differ from non-emergency patients in their consultation patterns and symptoms? A longitudinal data-linkage study in England. $\mathrm{Br} \mathrm{J}$ Cancer. 2016;115(7):866-75.

67. Bailey SER, Ukoumunne OC, Shephard EA, et al. Clinical relevance of thrombocytosis in primary care: a prospective cohort study of cancer incidence using English electronic medical records and cancer registry data. Br J Gen Pract. 2017;67(659):e405.

68. Watson J, Salisbury C, Banks J, et al. Predictive value of inflammatory markers for cancer diagnosis in primary care: a prospective cohort study using electronic health records. Br J Cancer. 2019;120(11): 1045-51.

69. Round T, Gildea C, Ashworth M, et al. Association between use of urgent suspected cancer referral and mortality and stage at diagnosis: a 5-year national cohort study. Br J Gen Pract. 2020;70(695):e389.

70. Mozdiak E, Weldeselassie Y, McFarlane M, et al. Systematic review with meta-analysis of over 90000 patients. Does fast-track review diagnose colorectal cancer earlier? Aliment Pharmacol Ther. 2019;50(4): 348-72.

71. Westwood M, Corro Ramos I, Lang S, et al. Faecal immunochemical tests to triage patients with lower abdominal symptoms for suspected colorectal cancer referrals in primary care: a systematic review and cost-effectiveness analysis. Health Technol Assess. 2017;21(33):1-234.

72. Westwood M, Lang S, Armstrong N, et al. Faecal immunochemical tests (FIT) can help to rule out 
colorectal cancer in patients presenting in primary care with lower abdominal symptoms: a systematic review conducted to inform new NICE DG30 diagnostic guidance. BMC Med. 2017;15(1):189.

73. Bailey S, Abel G, Atkins A, et al. Diagnostic performance of a faecal immunochemical test for patients with low-risk symptoms of colorectal cancer in primary care: an evaluation in the South West of England. Br J Cancer. 2021;124:1231-6.

74. van Melle M, Yep Manzano SIS, Wilson $H$, et al. Faecal immunochemical test to triage patients with abdominal symptoms for suspected colorectal cancer in primary care: review of international use and guidelines. Fam Pract. 2020;37(5):606-15.

75. Juul JS, Hornung N, Andersen B, et al. The value of using the faecal immunochemical test in general practice on patients presenting with non-alarm symptoms of colorectal cancer. $\mathrm{Br} \mathrm{J}$ Cancer. 2018;119(4):471-9.

76. Mowat C, Digby J, Strachan JA, et al. Impact of introducing a faecal immunochemical test (FIT) for haemoglobin into primary care on the outcome of patients with new bowel symptoms: a prospective cohort study. BMJ Open Gastroenterol. 2019;6(1): e000293.

77. Nicholson BD, James T, East JE, et al. Experience of adopting faecal immunochemical testing to meet the NICE colorectal cancer referral criteria for lowrisk symptomatic primary care patients in Oxfordshire. UK Frontline Gastroenterol. 2019;10(4): 347-55.

78. Högberg C, Gunnarsson U, Jansson S, et al. Diagnosing colorectal cancer in primary care: cohort study in Sweden of qualitative faecal immunochemical tests, haemoglobin levels, and platelet counts. Br J Gen Pract. 2020;70(701):e843.

79. Bailey SE, van Melle MA, Nicholson BD. Faecal immunochemical (rule-in) testing in general practice. Br J Gen Pract. 2019;69(681):178.

80. Chapman C, Thomas C, Morling J, et al. Early clinical outcomes of a rapid colorectal cancer diagnosis pathway using faecal immunochemical testing in Nottingham. Colorectal Dis. 2020;22(6): 679-88.

81. Hogberg C, Gunnarsson U, Cronberg O, et al. Qualitative faecal immunochemical tests (FITs) for diagnosing colorectal cancer in patients with histories of rectal bleeding in primary care: a cohort study. Int J Colorectal Dis. 2020;35(11):2035-40.

82. Von Wagner C, Stoffel ST, Freeman M, et al. General practitioners' awareness of the recommendations for faecal immunochemical tests (FITs) for suspected lower gastrointestinal cancers: a national survey. BMJ Open. 2019;9(4):e025737.

83. Maclean W, Limb C, Mackenzie P, et al. Adoption of faecal immunochemical testing for 2-week-wait colorectal patients during the COVID-19 pandemic: an observational cohort study reporting a new service at a regional centre. Colorectal Dis. 2020;17:17.

84. Sud A, Torr B, Jones ME, et al. Effect of delays in the 2-week-wait cancer referral pathway during the COVID-19 pandemic on cancer survival in the UK: a modelling study. Lancet Oncol. 2020;21(8): $1035-44$.

85. NICE. Specialty guides for patient management during the coronavirus pandemic. Clinical guide for triaging patients with lower gastrointestinal symptoms. 2020. https://www.nice.org.uk/Media/ Default/About/COVID-19/Specialty-guides/ triaging-patients-with-lower-gi-symptoms.pdf. Accessed 9 Apr 2021.

86. de Haan MC, van Gelder RE, Graser A, et al. Diagnostic value of CT-colonography as compared to colonoscopy in an asymptomatic screening population: a meta-analysis. Eur Radiol. 2011;21(8): 1747-63.

87. Obaro AE, Plumb AA, Fanshawe TR, et al. Postimaging colorectal cancer or interval cancer rates after CT colonography: a systematic review and meta-analysis. Lancet Gastroenterol Hepatol. 2018;3(5):326-36.

88. Jspeert J, Tutein Nolthenius CJ, Kuipers EJ, et al. CTcolonography vs. colonoscopy for detection of high-risk sessile serrated polyps. Am J Gastroenterol. 2016;111(4):516-22.

89. Atkin W, Dadswell E, Wooldrage K, et al. Computed tomographic colonography versus colonoscopy for investigation of patients with symptoms suggestive of colorectal cancer (SIGGAR): a multicentre randomised trial. Lancet. 2013;381(9873):1194-202.

90. Palimaka S, Blackhouse G, Goeree R. Colon capsule endoscopy for the detection of colorectal polyps: an economic analysis. Ont Health Technol Assess Ser. 2015;15(15):1-43.

91. NHS England. NHS rolls out capsule cameras to test for cancer. 2021. https://www.england.nhs.uk/ 2021/03/nhs-rolls-out-capsule-cameras-to-test-forcancer/. Accessed 9 Apr 2021.

92. NHS. Colon capsule endoscopy. 2020. https://www. nhsinform.scot/tests-and-treatments/non-surgicalprocedures/colon-capsule-endoscopy. Accessed 9 Apr 2021. 
93. Mori Y, Kudo S-E, Berzin TM, et al. Computer-aided diagnosis for colonoscopy. Endoscopy. 2017;49(8): 813-9.

94. NICE. ColonFlag for identifying people at risk of colorectal cancer. Medtech innovation briefing. 2018. http://www.nice.org.uk/guidance/mib142. Accessed 9 Apr 2021.

95. Williams TGS, Cubiella J, Griffin SJ, et al. Risk prediction models for colorectal cancer in people with symptoms: a systematic review. BMC Gastroenterol. 2016;16(1):63.

96. Grigore B, Lewis R, Peters J, et al. Development, validation and effectiveness of diagnostic prediction tools for colorectal cancer in primary care: a systematic review. BMC Cancer. 2020;20(1):1084.

97. Medina-Lara A, Grigore B, Lewis R, et al. Cancer diagnostic tools to aid decision-making in primary care: mixed-methods systematic reviews and costeffectiveness analysis. Health Technol Assess. 2020;24:66.

98. Hamilton W, Green T, Martins T, et al. Evaluation of risk assessment tools for suspected cancer in general practice: a cohort study. Br J Gen Pract. 2013;63(606):e30-6.

99. Hippisley-Cox J, Coupland C. Identifying patients with suspected colorectal cancer in primary care: derivation and validation of an algorithm. Br J Gen Pract. 2012;62(594):e29-37.

100. Hippisley-Cox J, Coupland C. Symptoms and risk factors to identify men with suspected cancer in primary care: derivation and validation of an algorithm. Br J Gen Pract. 2013;63(606):e1-10.

101. Hippisley-Cox J, Coupland C. Symptoms and risk factors to identify women with suspected cancer in primary care: derivation and validation of an algorithm. Br J Gen Pract. 2013;63(606):e11-21.

102. Macmillan Cancer Support. Cancer decision support (CDS) Tool. 2018. https://www.macmillan.org. uk/about-us/health-professionals/programmes-andservices/prevention-early-diagnosis-programme/ cancer-decision-support-tool.html. Accessed 9 Apr 2021.

103. ISRCTN22560297. Electronic risk assessment for cancer for patients in general practice (ERICA trial): ISRCTN. 2020. https://doi.org/10.1186/ ISRCTN22560297.

104. Price S, Spencer A, Medina-Lara A, et al. Availability and use of cancer decision-support tools: a crosssectional survey of UK primary care. Br J Gen Pract. 2019;69(684):e437.
105. Chiang PPC, Glance D, Walker J, et al. Implementing a QCancer risk tool into general practice consultations: an exploratory study using simulated consultations with Australian general practitioners. Br J Cancer. 2015;112(Suppl 1):S77-83.

106. Robinson S, Poirier V, Watson S. Using Cancer Decision Support Tools to support the early diagnosis of cancer. Accelerate, Coordinate, Evaluate (ACE) Programme. ACE Cancer Decision Support Tools Cluster. Cancer Research UK, Macmillan Cancer Support and NHS England; 2017.

107. Elias SG, Kok L, de Wit NJ, et al. Is there an added value of faecal calprotectin and haemoglobin in the diagnostic work-up for primary care patients suspected of significant colorectal disease? A crosssectional diagnostic study. BMC Med. 2016;14(1): 141.

108. Cubiella J, Vega P, Salve M, et al. Development and external validation of a faecal immunochemical test-based prediction model for colorectal cancer detection in symptomatic patients. BMC Med. 2016;14(1):128.

109. Cubiella J, Digby J, Rodríguez-Alonso L, et al. The fecal hemoglobin concentration, age and sex test score: development and external validation of a simple prediction tool for colorectal cancer detection in symptomatic patients. Int $\mathrm{J}$ Cancer. 2017;140(10):2201-11.

110. Digby J, Strachan JA, Mowat C, et al. Appraisal of the faecal haemoglobin, age and sex test (FAST) score in assessment of patients with lower bowel symptoms: an observational study. BMC Gastroenterol. 2019;19(1):213.

111. Vedsted P, Olesen F. A differentiated approach to referrals from general practice to support early cancer diagnosis-the Danish three-legged strategy. Br J Cancer. 2015;112(Suppl 1):S65-9.

112. Smeds M, Poksinska BB. The effects of cancer care pathways on waiting times. Int J Qual Serv Sci. 2019;11(2):204-16.

113. Nilssen Y, Brustugun OT, Eriksen MT, et al. Patient and tumour characteristics associated with inclusion in Cancer patient pathways in Norway in 2015-2016. BMC Cancer. 2020;20(1):488.

114. Lewis R. Improving diagnostic pathways for patients with vague symptoms. Accelerate, Coordinate, Evaluate (ACE) Programme. ACE Vague Symptoms Cluster. Cancer Research UK, Macmillan Cancer Support and NHS England; 2017.

115. Nicholson BD, Oke J, Friedemann Smith C, et al. The Suspected CANcer (SCAN) pathway: protocol for evaluating a new standard of care for patients 
with non-specific symptoms of cancer. BMJ Open. 2018;8(1):e018168.

116. Accelerate Coordinate Evaluate (ACE) Programme. Improving diagnostic pathways for patients with suspected colorectal cancer. Final report. 2017. https://www.cancerresearchuk.org/sites/default/ files/ace_-_improving_diagnostic_pathways_for_ patients_with_suspected_colorectal_cancer_-_final_ report_v1.0_270617_0.pdf. Accessed 9 Apr 2021.

117. NHS England, NHS Improvement. Rapid Diagnostic Centres. Vision and 2019/20 implementation specification. 2019. https://www.england.nhs.uk/wpcontent/uploads/2019/07/rdc-vision-and-1920implementation-specification.pdf. Accessed 9 Apr 2021.

118. NHS England. The NHS long term plan 2019. https://www.longtermplan.nhs.uk/wp-content/ uploads/2019/08/nhs-long-term-plan-version-1.2. pdf. Accessed 9 Apr 2021.

119. Brown S, Castelli M, Hunter DJ, et al. How might healthcare systems influence speed of cancer diagnosis: a narrative review. Soc Sci Med. 2014;116(100):56-63.

120. Vedsted P, Olesen F. Are the serious problems in cancer survival partly rooted in gatekeeper principles? An ecologic study. Br J Gen Pract. 2011;61(589):e508.

121. Greenfield G, Foley K, Majeed A. Rethinking primary care's gatekeeper role. BMJ. 2016;354:i4803.

122. Department of Health. Direct access to diagnostic tests for cancer. best practice referral pathways for general practitioners. 2012. https://www.assets. publishing.service.gov.uk/government/uploads/ system/uploads/attachment_data/file/216503/dh_ 133511.pdf. Accessed 9 Apr 2021.

123. Smith CF, Tompson AC, Jones N, et al. Direct access cancer testing in primary care: a systematic review of use and clinical outcomes. Br J Gen Pract. 2018;68(674):e594.
124. NICE. Suspected cancer. Quality standard [QS124]. 2016. https://www.nice.org.uk/guidance/qs124. Accessed 9 Apr 2021.

125. Nicholson BD, Oke JL, Rose PW, et al. Variation in direct access to tests to investigate cancer: a survey of English general practitioners. PLoS One. 2016;11(7):e0159725.

126. Cohen JD, Li L, Wang Y, et al. Detection and localization of surgically resectable cancers with a multi-analyte blood test. Science. 2018;359(6378): 926.

127. Liu MC, Oxnard GR, Klein EA, et al. Sensitive and specific multi-cancer detection and localization using methylation signatures in cell-free DNA. Ann Oncol. 2020;31(6):745-59.

128. Hariharan R, Jenkins M. Utility of the methylated SEPT9 test for the early detection of colorectal cancer: a systematic review and meta-analysis of diagnostic test accuracy. BMJ Open Gastroenterol. 2020;7(1):e000355.

129. Nian J, Sun X, Ming S, et al. Diagnostic accuracy of methylated SEPT9 for blood-based colorectal cancer detection: a systematic review and meta-analysis. Clin Transl Gastroenterol. 2017;8(1):e216.

130. Worm Ørntoft MB. Review of blood-based colorectal cancer screening: how far are circulating cell-free DNA methylation markers from clinical implementation? Clin Colorectal Cancer. 2018;17(2): e415-33.

131. Druce P, Calanzani N, Snudden C, et al. Identifying novel biomarkers ready for evaluation in lowprevalence populations for the early detection of lower gastrointestinal cancers: a systematic review and meta-analysis. Adv Ther. 2021; https://doi.org/ 10.1007/s12325-021-01645-6.

132. Walter FM, Thompson MJ, Wellwood I, et al. Evaluating diagnostic strategies for early detection of cancer: the CanTest framework. BMC Cancer. 2019;19(1):586. 